\title{
PELATIHAN PEMANFAATAN UMBUT ROTAN, BIJI KARET DAN BAWANG DAYAK SEBAGAI BAHAN BAKU PRODUK KEWIRAUSAHAAN
}

\author{
Rina Masithoh ${ }^{1^{*}}$, Catur Kumala Dewi ${ }^{2}$, Sunarto $^{3}$, Titin Ruliana ${ }^{4}$ \\ 1,2,3,4 Universitas 17 Agustus 1945 Samarinda \\ *E-mail: rinamasithoh@gmail.com
}

\begin{abstract}
ABSTRAK
Desa Budaya Sungai Bawang merupakan desa budaya sekaligus desa definitif yang ditetapkan oleh pemerintah daerah Kutai Kertanegara per tanggal 14 Januari 2008. Salah satu potensi lokal yang terabaikan dari Desa Budaya Sungai Bawang adalah umbut rotan, biji karet dan bawang Dayak. Ketiga bahan baku tersebut oleh mahasiswa Fakultas Ekonomi Universitas 17 Agustus 1945 Samarinda dalam mata kuliah kewirausahaan diolah menjadi keripik dan kerupuk. Oleh karena itu maka pihak Fakultas Ekonomi Universitas 17 Agustus 1945 Samarinda perlu memperkenalkan potensi lokal tersebut dan memberikan penyuluhan dan pengarahan kepada masyarakat Desa Budaya Sungai Bawang tentang cara pengolahan yang benar. Ketiga potensi lokal tersebut diolah menjadi keripik yang dapat dikonsumsi sendiri bahkan dengan kemasan yang menarik maka dapat dijual sebagai pendapatan masyarakat khususnya ibu rumah tangga Desa Budaya Sungai Bawang.
\end{abstract}

Kata kunci: Umbut Rotan, Biji Karet, Bawang Dayak, Desa Budaya Sungai Bawang

\section{TRAINING ON UTILIZATION OF RATTAN STEM TIP, RUBBER SEED AND DAYAK ONION AS RAW MATERIALS FOR ENTREPRENEURIAL PRODUCTS}

\begin{abstract}
Sungai Bawang Cultural Village is a cultural village as well as a definitive village established by the government of Kutai Kertanegara as of January 14, 2008. One of the overlooked local potentials of the Sungai Bawang Cultural Village is rattan stem tip, rubber seeds and Dayang onions. The three raw materials are processed into chips by the students of Faculty of Economics, Universitas 17 Agustus 1945 Samarinda in the entrepreneurship course. Therefore, the Faculty of Economics Universitas 17 Agustus 1945 Samarinda needs to introduce the local potential and provide counseling and guidance to the people of Sungai Bawang Cultural Village regarding the correct processing method. The three local potentials are processed into chips that can be either for personal consumption or with attractive packaging; they can be sold to boost community income, especially housewives of Sungai Bawang Cultural Village.
\end{abstract}

Keywords: Rotan Wood, Rubber Seed, Dayak Onion, Sungai Bawang Cultural Village

\section{PENDAHULUAN}

Wirausaha merupakan alternatif pilihan yang tepat untuk mengatasi masalah pengangguran [2]. Kewirausahaan merupakan salah satu mata kuliah yang diberikan kepada mahasiswa Fakultas Ekonomi semester ganjil Universitas 17 Agustus 1945. Mata kuliah kewirausahaan memberikan kebebasan kepada para mahasiswa untuk berkreasi dalam hal menciptakan produk-produk baru yang bahan utamanya berbasis potensi lokal. Produk-produk dari para mahasiswa diseleksi oleh para dosen pengasuh dan telah diikutsertakan dalam ajang National Business Plan Competition 2019 di Universitas Bangka Belitung yang diselenggarakan pada 29 April 2019 sampai dengan 02 Mei 2019. Ajang teresebut diikuti oleh 10 besar finalis dari 6 perguruan tinggi antara lain Universitas Negeri Yogyakarta, Universitas Bangka Belitung, Universitas Lambung Mangkurat, Universitas Muhammadiyah Surakarta, Universitas Islam Negeri Walisongo dan Universitas 17 Agustus 1945 Samarinda.

Atas dasar hal ini maka Fakultas Ekonomi Universitas 17 Agustus 1945 Samarinda merasa perlu untuk mengembangkan produk yang telah diikutsertakan dalam ajang National Business Plan Competition 2019 untuk dapat diperkenalkan kepada para masyarakat dimana potensi lokal banyak ditemukan. Pengenalan produk yang telah memiliki added value dari potensi lokal yang biasanya oleh 
BAKTI BANUA : Jurnal Pengabdian Kepada Masyarakat

Volume 1 No. 2 November 2020

e-ISSN : 2722-3736

p-ISSN : 2722-7529

https://ejurnal.stimi-bjm.ac.id/index.php/BBJM/

masyarakat sekitar dianggap hal biasa perlu untuk dikenalkan agar masyarakat bertambah wawasannya tentang potensi tersebut. Fakultas Ekonomi Universitas 17 Agustus 1945 Samarinda mengadakan pengabdian di Desa Bawang. Hal ini dilakukan untuk meningkatkan motivasi berwirausaha mitra baik secara individu maupun secara kelompok.

Sekilas sejarah tentang Desa Bawang dimana sebelum tahun 2005 nama pemukiman ini adalah Kampung Dayak atau Kampung Karangmumus Dalam. Setelah tahun 2005 ditetapkan oleh pemerintah sebagai desa persiapan desa Budaya Sungai Bawang. Jumlah penduduk desa Budaya Sungai Bawang berjumlah 360 Kepala Keluarga, terdiri dari 1.624 jiwa yang tersebar di 5 wilayah RT dengan luas desa seluas $1680 \mathrm{Ha}^{2}$. Batas-batas daerah desa Budaya Sungai Bawang di sebelah barat berbatasan dengan Samarinda (desa budaya Pampang), sebelah utara berbatasan dengan Badak Mekar Kecamatan Muara Badak, sebelah timur berbatasan dengan Tanah Datar Kecamatan Muara Badak dan sebelah selatan berbatasan dengan Tanah Datar dan Samarinda tepatnya dengan Bandara APT Pranoto Samarinda. Bulan Oktober di minggu ketiga dan keempat merupakan bulan kalender masa menanam padi atau yang biasa oleh masyarakat disebut manunggal merupakan masa tahunan dalam menanam padi baik padi sawah maupun padi gunung. Pola kerja menanam padi atau manunggal dilakukan secara gotong royong, hingga di awal bulan November semua kegiatan menanam padi atau manuggal telah selesai.

Potensi lokal merupakan kearifan lokal yang dapat di temukan di Budaya Sungai Bawang bahkan merupakan bahan-bahan yang biasanya dikonsumsi oleh masyarakat setempat. Potensi lokal yang berbasis kearifan lokal salah satunya merupakan umbut rotan, bawang Dayak dan biji karet. Bahan tersebut banyak tersedia di desa Budaya Sungai Bawang bahkan belum termanfaatkan secara finansial. Tidak termanfaatkannya bahan baku tersebut merupakan masalah yang pasti membutuhkan solusi [8]. Bahan-bahan tersebut bahkan hanya terbuang percuma dan sebagian diberikan untuk makanan hewan peliharaan (anjing dan babi). Umbut rotan terbuat dari umbut atau rotan muda sedangkan bawang Dayak segar memiliki kadar air 62,31\%, kadar abu 6,2\% dan vitamin C 16,1 $\mathrm{mg} / 100 \mathrm{~g}$. Masalah utama dalam pemanfaatan biji karet adalah kandungan senyawa toksik asam sianida $(\mathrm{HCN})$ yang cukup tinggi, meskipun kandungan $\mathrm{HCN}$ dalam biji karet segar cukup tinggi tetapi setelah dibuat tempe mengalami penurunan kadar HCN yang drastis hingga menjadi 17,50 ppm [4]. Jika kegiatan ini dilakukan secara rutin,maka diharapkan minat masyarakat terhadap dunia pertanian dan pengolahan hasil pertanian khususnya daerah marginal dapat terus ditumbuh kembangkan,sehingga kesejahteraan petani di masa yang akan datang dapat ditingkatkan dan terbentuknya industri rumahan (home industry) pengolahan hasil pertanian.

\section{Permasalahan yang dihadapi Masyarakat Desa Budaya Sungai Bawang}

Permasalahan utama yang dihadapi oleh masyarakat adalah Desa Budaya Sungai Bawang adalah banyaknya ketersediaan bahan baku umbut rotan, biji karet dan bawang Dayak di daerah tersebut. Ketiga bahan baku tersebut dinilai masyarakat sebagai sampah yang tidak memiliki potensi untuk diberi nilai tambah.

\section{Tujuan Pengabdian Kepada Masyarakat}

Dari permasalahan yang ada maka dilakukan pengabdian kepada masyarakat dengan tujuan:

1. Memperkenalkan potensi lokal kepada masyarakat Desa Budaya Sungai Bawang

2. Memberikan penyuluhan dan pengarahan kepada masyarakat Desa Budaya Sungai Bawang cara mengolah potensi lokal dari umbut rotan, biji karet dan bawang Dayak

3. Pembinaan lebih lanjut untuk Desa Budaya Sungai Bawang sebagai desa binaan Fakultas Ekonomi Universitas 17 Agustus 1945

\section{Manfaat Pengabdian Kepada Masyarakat}

Bagi masyarakat Desa Budaya Desa Bawang diharapkan setelah pelatihan diberikan maka dapat:

1. Menggali potensi lokal sebagai cirri khas dari Desa Sungai Bawang 
BAKTI BANUA : Jurnal Pengabdian Kepada Masyarakat

Volume 1 No. 2 November 2020

e-ISSN : 2722-3736

p-ISSN : 2722-7529

https://ejurnal.stimi-bjm.ac.id/index.php/BBJM/

2. Mengembangkan pengadaan sumber bahan baku untuk jangka panjang agar rantai pasok terjaga

3. Mengolah dengan tepat umbut rotan, biji karet dan bawang Dayak sebagai makanan ringan

4. Memanfaatkan status desa budaya untuk memasarkan produk yang telah dikemas dengan menarik

\section{METODE}

\section{Lokasi Pengabdian}

Pelatihan yang diberikan kepada para masyarakat Desa Budaya Sungai Bawang yang bertempat di Lamin Jl. Anyeq Apui RT 03 pada hari Sabtu tanggal 02 November 2019 di Desa Budaya Sungai Bawang.

\section{Metode yang Digunakan}

Kegiatan pelatihan dilaksanakan selama satu hari di tanggal 02 November 2019 dengan metode yang dilakukan sebagai berikut:

1. Perkenalan potensi lokal yang memiliki nilai tambah dan belum termanfaatkan secara tepat yaitu umbut rotan, biji karet dan bawang Dayak

2. Memberikan pelatihan pertama berupa demo pengolahan dari umbut rotan dan bawang Dayak menjadi kerupuk:

a. Pemilihan umbut rotan dan bawang Dayak yang telah dihaluskan

b. Pencampuran bumbu dan tepung umbut rotan atau bawang Dayak dengan rasio 1:1

c. Perebusan campuran bahan dalam panic hingga bahan tenggelam dengan metode 5 menit rebus, 30 menit matikan api dan jangan buka tutup panci lalu rebus kembali selama 7 menit. Metode ini untuk mengurangi pemakaian gas elpiji.

d. Pemotongan adonan dengan menggunakan gunting

e. Penjemuran dengan memanfaatkan terik matahari hingga 3 hari

f. Penggorengan keripik dan pengemasan

3. Memberikan pelatihan kedua berupa demo pengolahan dari biji karet menjadi kerupuk:

a. Pemilihan bahan baku biji karet dengan cangkang utuh

b. Pengupasan kulit ari biji karet

c. Perendaman biji karet selama 1 x 24 jam

d. Perebusan biji karet selama 1 jam

e. Pengirisan biji karet dengan menghilangkan terlebih dahulu bakal daun

f. Perendaman kembali biji karet selama 1 x 24 jam (perendaman dilakukan berulang untuk menghilangkan kandungan sianida dalam biji karet)

g. Pengukusan biji karet selama 30 menit

h. Pengeringan biji karet

i. Pemberian ragi biji karet hingga terfermentasi selama $2 \times 24$ jam

j. Penggorengan tempe biji karet dengan adonan tepung hingga menjadi keripik biji karet

4. Perkenalan pentingnya kemasan untuk hasil olahan umbut rotan, bawang Dayak dan biji karet agar menarik di rasa dan mata

\section{Ruang Lingkup Pengabdian}

Ruang lingkup dari kegiatan pengabdian berupa pelatihan pemanfaatan umbut rotan, biji karet dan bawang Dayak kepada masyarakat Desa Budaya Sungai Bawang dimana bahan bakunya merupakan potensi lokas daerah Sungai Bawang.

\section{Peserta Kegiatan Pengabdian}

Peserta kegiatan pengabdian ini diikuti oleh:

1. Masyarakat desa Budaya Desa Sungai Bawang

2. Dosen Fakultas Ekonomi Universitas 17 Agustus 1945 Samarinda

3. Senat mahasiswa Fakultas Ekonomi Universitas 17 Agustus 1945 Samarinda 
BAKTI BANUA : Jurnal Pengabdian Kepada Masyarakat

Volume 1 No. 2 November 2020

e-ISSN : 2722-3736

p-ISSN : 2722-7529

https://ejurnal.stimi-bjm.ac.id/index.php/BBJM/

4. Mahasiswa angakatan tahun 2019 Fakultas Ekonomi Universitas 17 Agustus 1945 Samarinda

\section{Prosedur Kegiatan Pengabdian}

Sebelum pelaksanaan pada tanggal 22 Oktober 2019 para perwakilan dosen dan mahasiswa melakukan pra kunjungan ke Desa Sungai Bawang untuk membicarakan pelatihan yang akan diadakan pada tanggal 02 November 2019. Kegiatan pengabdian dilakukan dengan memberikan pelatihan berupa demo tersebut terbagi menjadi dua sesi dimana sesi pertama adalah demo pengolahan kerupuk umbut rotan dan bawang dayang. Cara pengolahan umbut rotan dan bawang Dayak menjadi kerupuk melalui tahapan yang sama sehingga kedua bahan baku tersebut diwakili oleh pengolahan umbut rotan. Sesi kedua diisi dengan demo pengolahan biji karet sebagai keripik.

\section{HASIL DAN PEMBAHASAN}

Pemilihan Desa Budaya Sungai Bawang sebagai penjajagan perkenalan kerupuk dan keripik berbahan baku umbut rotan, bawang Dayak dan biji karet adalah selain penetapan desa definitif, bahan baku utama yang diperlukan adalah hasil tumbuhan lokal di Desa Budaya Sungai Bawang. Sebaiknya dilakukan pelatihan lanjutan hingga menjadi mitra binaan mengingat minat masyarakat desa yang antusias tentang bahan baku baku umbut rotan, bawang Dayak dan biji karet menjadi panganan merupakan hal yang baru. Perlunya menjaga ketersediaan bahan baku sehingga umbut rotan, bawang Dayak dan biji karet dapat dikembangkan menjadi lahan pertanian.

Tim pengadaan latihan mempersiapkan bahan dan alat yang akan digunakan untuk demo yang meliputi alat masak seperti: kompor, wajan, wadah, talenan, gunting, dll; untuk bahan disediakan bahan mentah hingga bahan setengah jadi untuk menunjukkan pada para peserta (masyarakat) hasil olahan bahan setengah jadi hingga perlakuan bahan menjadi barang siap makan. Tim memberikan tips kepada para peserta dalam hal menyiasati lamanya perebusan yang dapat membuat pemakaian gas elpiji membengkak yaitu dengan metode 5, 30, 7. Perebusan awal dilakukan 5 menit pertama dengan posisi panci tertutup, setelah 5 menit maka api kompor dapat dimatikan hingga menunggu 30 menit dalam keadaan tutup panci tidak boleh terbuka dan 7 menit terakhir dilakukan perubusan kembali. Sedangkan untuk tips pemilihan biji karet juga dipaparkan oleh tim agar para peserta paham cara memilih biji karet yang benar hingga memperoleh bahan yang tepat. Selain hal itu, tim juga memberikan tips bagaiman mengurangi bahkan menghilangkan kadar $\mathrm{HCN}$ atau sianida dalam biji karet yaitu dengan mengikuti prosedur perendaman yang tepat.

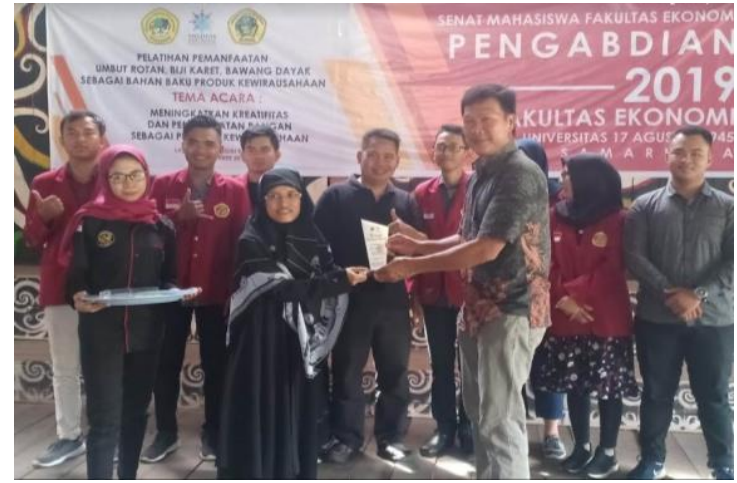

Gambar 1. Penyerahan Plakat kepada Kades Bapak Martinus

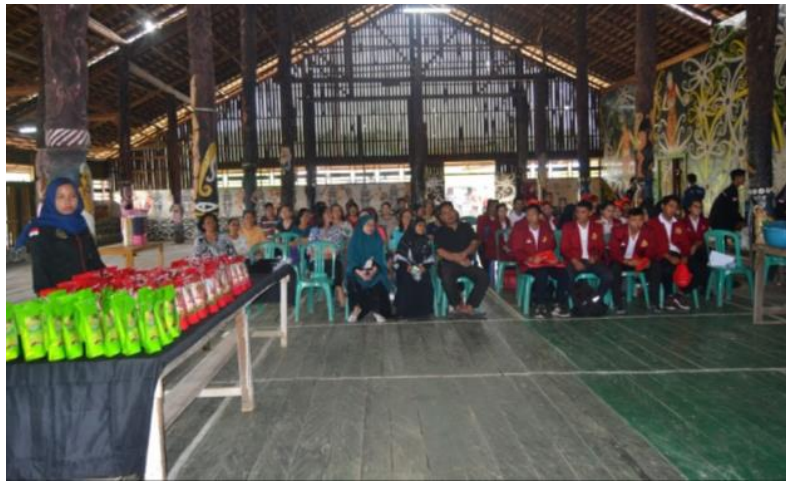

Gambar 2. Peserta dan Panitia 


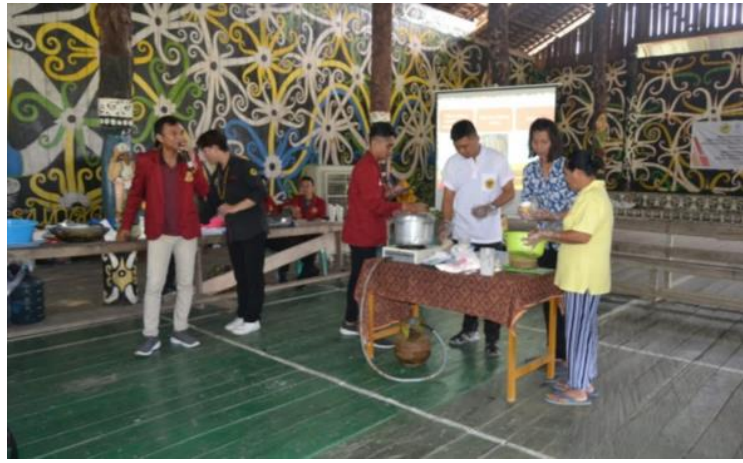

Gambar 3. Demo Produk umbut rotan dan bawang Dayak

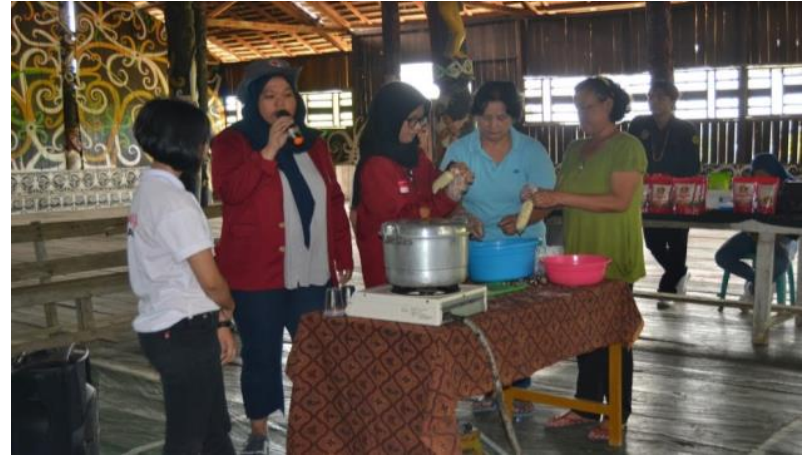

Gambar 4. Demo Produk Keripik Biji Karet

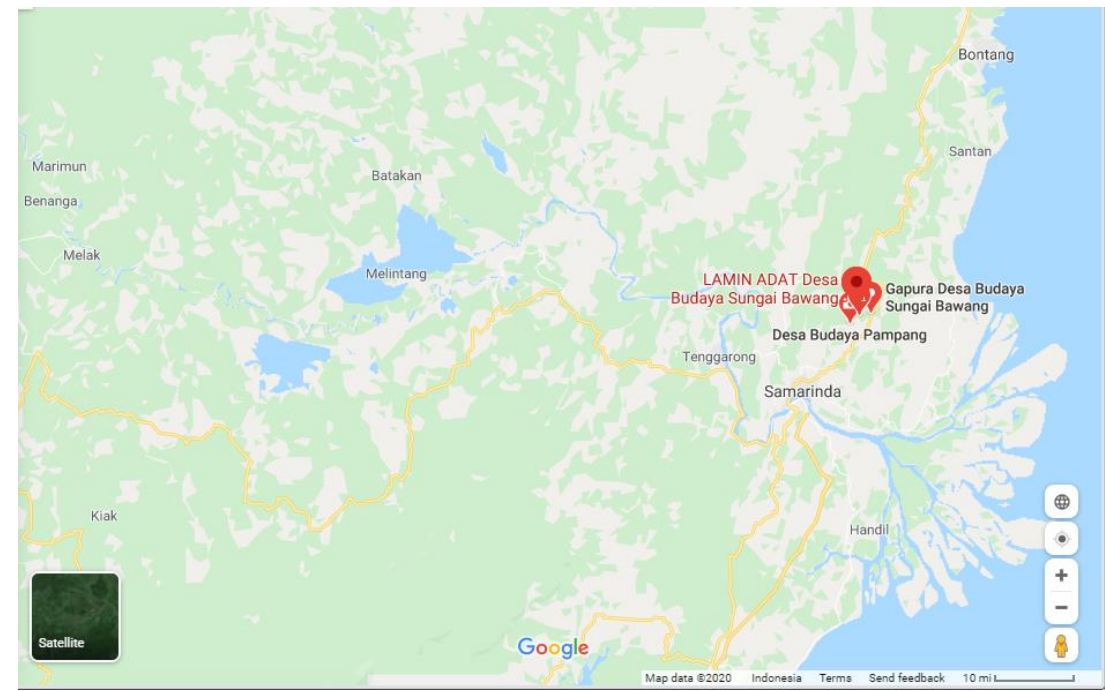

Sumber: google maps, 2020 [1]

Gambar 5. Peta Lokasi Desa Budaya Sungai Bawang

\section{SIMPULAN}

Pelatihan pengolahan yang dilakukan oleh para peserta membuka cakrawala para masyarakat Desa Budaya Sungai Bawang bahwa potensi lokal seperti umbut rotan, biji karet dan bawang Dayak memiliki nilai lebih dengan pengolahan yang tepat sehingga dapat dijadikan sebagai salah satu sumber pengasilan masyarakat sekitar bahkan dapat dijadikan hasil olahan ciri khas dari Desa Budaya Sungai Bawang mengingat bahan bakunya berasal dari daerah setempat

\section{UCAPAN TERIMAKASIH}

Kepada Kepala Desa Bapak Marthinus dan masyarakat Desa Budaya Sungai Bawang. Dekan Fakultas Ekonomi, dosen, staf administrasi dan para mahasiswa Universitas 17 Agustus 1945 Samarinda.

\section{DAFTAR PUSTAKA}

Google Maps. 2020. Lokasi Desa Budaya Sungai Bawang. https://goo.gl/maps/FsMPxefzS69i3Lmy5. Diakses tanggal 03 Mei 2020.

Hardi, H, N. Lubis dan E. Sofiyanti.2018. Kewirausahaan bagi Ibu-Ibu Rumah Tagga Kelurahan Sungai Sibam Kecamatan Payung Sekaki Kota Pekanbaru. Jurnal Manajemen Pendidikan dan Pelatihan 2(2) 113-120. 
BAKTI BANUA : Jurnal Pengabdian Kepada Masyarakat

Volume 1 No. 2 November 2020

e-ISSN : 2722-3736

p-ISSN : 2722-7529

https://ejurnal.stimi-bjm.ac.id/index.php/BBJM/

Ismail dan Jhony Syafwandhinata. 2020. ibM Pelatihan, Pembinaan dan Pendampingan Bidang Kerajinan, Souvenir, Sablon dan Percetakan. Jurnal Pengabdian Kepada Masyarakat 1(1) 1-9

Marseno, Djagal W. 2008. Prosiding Seminar Nasional Makanan Tradisional.

Marta, H. dan Tensiska. 2013. Pembuatan Berbagai Produk Ubi Jalar dalam Upaya Diversifikasi Pangan dan Peningkatan Gizi Masyarakat di Desa Sekarwangi dan Desa Cilangkap Kecamatan Buahdua Kabupaten Sumedang. Dharmakarya: Jurnal Aplikasi Ipteks untuk Masyarakat. 2(2) 85-92

Saragih Bernatal. 2018. Bawang Dayak (tiwai) sebagai Pangan Fungsional. Yogyakarta: Deepublish

Saragih, Bernatal dkk. 2018. Pangan Olahan Etnis Dayak Kutai Barat. Yogyakarta: Deepublish

Widyasanti, A., Putri S.H. dan Dwiratna S.N.P. 2016. Upaya Pemberdayaan Masyarakat melalui Pelatihan Pembuatan Produk Sabun Berbasis Komoditas Lokal di Kecamatan Sukamantri Ciamis. Dharmakarya: Jurnal Aplikasi Ipteks untuk Masyarakat. 5(1) 29-33 